\title{
Impact of the Affordable Care Act on Health Care Access and Utilization Among Latinos
}

\author{
Héctor E. Alcalá, PhD, Jie Chen, PhD, Brent A. Langellier, PhD, Dylan H. Roby, PhD, \\ and Alexander N. Ortega, PhD
}

Introduction: In the United States, Latinos have poorer access to and utilization of health care than non-Latino whites. The Patient Protection and Affordable Care Act (ACA) may reduce these disparities. The ACA's impact among Latino subgroups is unknown.

Methods: Using the 2011 to 2015 National Health Interview Survey, we examined access to and utilization of health care by Latino subgroups (18-64 years old). Subgroups were defined by Latino heritage group, citizenship status, and language use. Measures of access and utilization included insurance status, delaying medical care, forgoing medical care, visiting the emergency department, and visiting a physician. Logistic regression models were used to estimate the odds of the outcomes. Time period and subgroup interaction terms were used to test the effects of the ACA.

Results: Mexicans and Central Americans had lower odds of being insured than did non-Latino whites. After ACA implementation, most reductions in disparities occurred between Puerto Ricans and non-Latino whites. Limited impact of the ACA was observed by language and citizenship status.

Conclusions: The ACA has reduced gaps in access to and utilization of health care for some Latino population subgroups. Remaining disparities necessitate policy solutions that move beyond the ACA, particularly for groups excluded from coverage options, such as noncitizens. (J Am Board Fam Med 2017;30:52-62.)

Keywords: Emergency Service, Hospital; Hispanic Americans; Insurance Coverage; Language; Logistic Models; Patient Protection and Affordable Care Act; Surveys and Questionnaires

With the rollout of provisions in the Patient Protection and Affordable Care Act (ACA), the percentage of uninsured Americans has dropped from $20 \%$ in 2010 to $16 \%$ in $2014 .{ }^{1}$ Expansion of coverage to young adults and elimination of cost-sharing for some preventive services have led to an increase in the use of some, but not all, health services. $^{2-4}$ The implementation of key ACA pro-

This article was externally peer reviewed.

Submitted 28 June 2016; revised 9 September 2016; accepted 19 September 2016.

From the Department of Public Health Sciences, School of Medicine, University of Virginia, Charlottesville (HEA); the Department of Health Services Administration, School of Public Health, University of Maryland, College Park (JC, DHR); and the Department of Health Management and Policy, Dornsife School of Public Health, Drexel University, Philadelphia, PA (BAL, ANO).

Funding: none.

Conflict of interest: none declared.

Corresponding author: Héctor E. Alcalá, PhD, Postdoctoral Research Associate, Department of Public Health Sciences, University of Virginia, 560 Ray C. Hunt Dr., Charlottesville, VA 22903 (E-mail: hectorapm@ucla.edu). visions in 2014 (ie, Medicaid expansion, creation of insurance exchanges, provision of subsidies for the purchase of insurance, the individual mandate, and changes to insurance pricing, benefits, and accessibility $)^{5}$ has also led to improved access to and utilization of care. ${ }^{6}$

Despite gains, racial and ethnic disparities remain: Latinos perform worse on most measures of access and utilization than non-Latino whites. ${ }^{6}$ Reasons for these persistent disparities are multifaceted but include factors such as citizenship status, language, socioeconomic factors, ${ }^{7}$ and a lack of awareness of the ACA's provisions, ${ }^{8}$ and these make it difficult for Latinos to benefit from the law. To understand the full impact of the ACA on health care disparities among Latinos, it is important to examine not only disparities in access and utilization between racial and ethnic groups (eg, Latinos vs nonLatino whites) but also how the ACA has affected outcomes within groups based on factors such as Latino heritage group, language, and nativity. 
Evidence suggests that the impact of the ACA among Latinos has differed by language spoken and limited English proficiency (LEP). In Oregon, the percentage of Spanish-speaking Latinos without insurance dropped from $64.3 \%$ before the implementation of the ACA to $13.7 \%$ after Medicaid was expanded in the state. ${ }^{9}$ Similarly, California's early expansion of coverage through a waiver made possible by $\mathrm{ACA}^{10,11}$ resulted in the greatest gains in public coverage among Latinos with LEP. ${ }^{12}$ The large benefits experienced by Spanish-speaking Latinos may be due to the large proportion of the group living in households with an income below eligibility thresholds for Medicaid expansion, as well as previous patterns of poor use of health care services among Spanish-speaking Latinos ${ }^{13-15}$ before the ACA.

Before the ACA, foreign-born Latinos had a more negative pattern of access to and utilization of health care than did their US-born counterparts. ${ }^{16-18}$ This is partially attributable to the poorer patterns of access to and utilization of health care among noncitizens, with undocumented individuals being of particular concern. ${ }^{16,19}$ For example, even when accounting for insurance status, noncitizens and undocumented individuals use primary care and emergency department (ED) care at lower rates than US citizens. ${ }^{19,20}$ These patterns may stem from the unique barrier presented by fears that health care will be denied because of documentation status or that they will be deported if they attempt to seek care. ${ }^{21,22}$ This and other barriers, such as cost of care and lack of languageconcordant care, may drive undocumented and noncitizen individuals to return to their home countries to seek care ${ }^{23-25}$ thus adding the barrier of international travel for accessing health services. Because the ACA excludes undocumented individuals from benefits, the impact of the ACA's implementation will be limited for this group. ${ }^{26}$ Over time, a larger proportion of the remaining uninsured are likely to be undocumented. ${ }^{27}$

Research in disparities in access to and utilization of health care by different Latino heritage groups has received limited attention in the period after ACA implementation. However, disparities were documented before the ACA. For example, Mexican-heritage Latinos had the lowest rates of insurance coverage and Puerto Ricans had the highest. ${ }^{28}$ Similar patterns are observed when examining use of health care services by heritage group. ${ }^{18,29-32}$ Differences by heritage group are not surprising given that some groups-by virtue of being US citizens (ie, Puerto Ricans) or being granted refugee status (ie, Cubans)- have easier access to insurance and health care than groups who have higher proportions of undocumented individuals (ie, Mexican and Central Americans). ${ }^{7,33}$ Relatedly, underlying socioeconomic differences between groups ${ }^{34}$ suggest differential gains under the ACA due to income thresholds for expanded coverage options.

This study examines the impact of policies implemented in 2014 as part of the ACA regarding access to and utilization of health care (ie, insurance status, delays in medical care, forgoing medical care, physician visits, and visits to the ED) among Latino population subgroups. We have the following 3 aims: (1) to examine trends in access to and utilization of health care by Latino heritage groups; (2) to determine the independent effects of heritage group, nativity, and language on access to and utilization of health care; and (3) to determine the independent effects of the ACA provisions implemented in 2014 on access to and utilization of health care by heritage group, language, and nativity. Results highlight subgroups of the Latino population on whom the initial insurance expansion of the ACA has had limited impact.

\section{Methods \\ Data}

Data for this study come from the 2011 to 2015 waves of the National Health Interview Survey (NHIS). This annual survey is representative of noninstitutionalized adults in the United States. This study was restricted to the 65,703 non-Latino whites and 20,764 Latino adults (1,995 Puerto Ricans, 12,983 Mexicans, 871 Cubans, 3,592 Central Americans, and 1,323 other Latinos) who were between 18 and 64 years old, had complete data for all variables used in the analyses, and did not identify with more than 1 Latino heritage group.

\section{Measures}

Outcomes of interest encompassed frequently used measures of access to and utilization of health care. ${ }^{6,35,36}$ Access indicators included dichotomous measures of (1) health insurance status (currently insured); (2) delaying necessary medical care, excluding dental care, because of costs in the past 12 
months; and (3) forgoing necessary medical care, excluding dental care, because of costs in the past 12 months. Utilization indicators included dichotomous measures of (1) having had at least 1 ED visit in the past 12 months, even if this visit resulted in admission to the hospital; and (2) having had a physician (in general practice, family medicine, or internal medicine) visit in the past 12 months.

Key grouping variables included a measure of Latino heritage group or race (non-Latino white, Central American, Cuban, Mexican, Puerto Rican, and other Latino), citizenship status (US-born, naturalized citizen, and noncitizen), and language of survey administration (English, Spanish, and other language). While the ACA excludes specific noncitizen groups (ie, undocumented or legally authorized but in the country $<5$ years) from benefits, ${ }^{26,37}$ some noncitizens do qualify for benefits, and their eligibility varies by state (eg, California allows the undocumented to participate in the Marketplace, and legally authorized immigrants who have been in the US $<5$ years can participate in Medicaid); thus noncitizens were included in the analyses.

To understand how access to and use of health care changed over time as provisions of the ACA were implemented, variables representing the year of the NHIS survey were included in some models (Table 2). In other models (Tables 3 and 4), a dichotomous measure of time period (before the ACA and after the ACA) was included. The period before the ACA included NHIS data from 2011 to 2013, and the period after the ACA included NHIS data from 2014 and 2015. To understand whether changes over time varied between Latino subgroups, interaction terms between subgroup indicators and the dummy-coded variable for the time period were also included.

Several variables were included in analyses as potential confounders based on the literature ${ }^{6,38}$ : age (18-24, 25-34, 35-44, 45-54, or 55-64 years), sex (male or female), marital status (married or other), family income ( $<100 \%$, between $100 \%$ and $200 \%$, or $>200 \%$ of the federal poverty level), educational attainment (less than high school, high school, some college, college, or more than college), US Census region (Northeast, Midwest, South, or West), self-reported health status (excellent, very good, good, fair, or poor), chronic conditions (hypertension, coronary artery disease, heart condition/disease, asthma, cancer, or diabetes), and having functional limitations (yes or no).

\section{Analyses}

Statistical analyses were conducted by pooling the 2011 to 2015 waves of the NHIS. Analyses were conducted using Stata 14.0, using weights to provide estimates that were nationally representative. Descriptive statistics were calculated for each Latino heritage group, and the $\chi^{2}$ test was used to compare results by heritage group.

Logistic regression models were estimated for each of the 5 outcomes to determine whether year, Latino heritage group, citizenship status, and language of survey administration were associated with odds of the outcomes. These models included all aforementioned controls along with survey year, Latino heritage group, citizenship status, and language of survey administration (Table 2). Then models with 1 of the following interaction terms (along with the time period and grouping variable used to create the interaction) were run to test the hypothesis that the impact of ACA implementation varied by grouping variable: (1) heritage group $\times$ time period (Table 3); (2) citizenship status $\times$ time period (Table 4); and (3) language of survey administration $\times$ time period (Table 4 ). Thus interactions consisted of a grouping variable multiplied by a dummy variable for time period (before or after the ACA). For interpretation, only 1 of these interaction terms was entered into the model at a time. Stratified analyses were not conducted because odds ratios in stratified models, particularly when outcomes are not rare, are not comparable. ${ }^{39,40}$ Models for citizenship and language were restricted to Latino respondents, with the latter excluding individuals completing the NIHS in a language other than English or Spanish. Last, the outcome variables were plotted by year and Latino heritage group to allow for the examination of changes over time within a particular heritage group.

\section{Results}

\section{Trends in Access to and Utilization of Health Care}

Figure 1 depicts the trends in access to and utilization of health care by Latino heritage groups. Broadly speaking, from 2011 to 2015, access to and utilization of care improved among most groups, with notable exceptions for ED visits and forgoing care or delaying care among the "other Latino" 
Figure 1. Rates of access and utilization measures, by heritage group. Data from the 2011 to 2015 National Health Interview Survey $(\mathrm{N}=86,467)$.
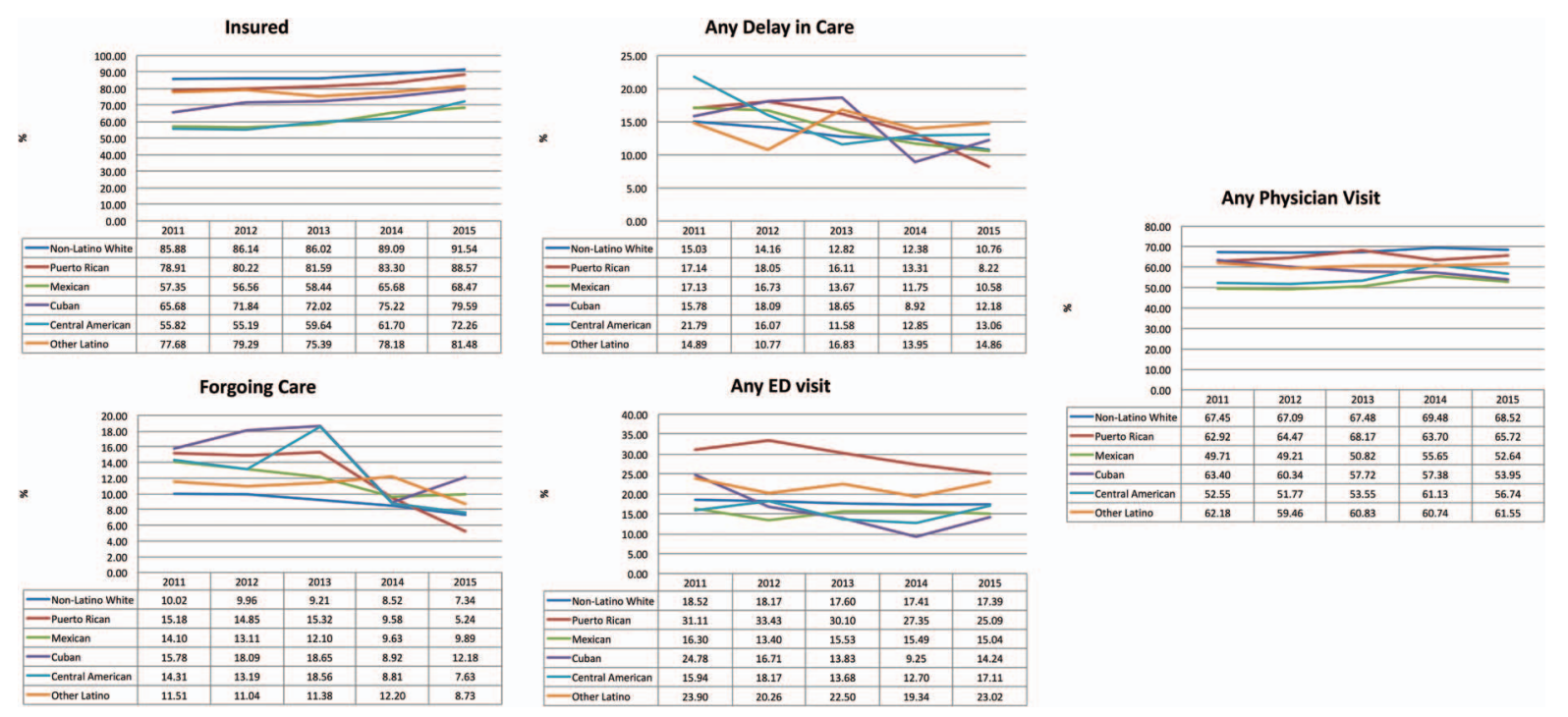

group. However, improvements were not linear; some groups saw improvement immediately after ACA provisions were enacted (ie, in 2014), only to lose ground in the subsequent year. Specifically, some groups saw poorer patterns of delaying care (Cubans, Central Americans, and other Latinos), forgoing care (Mexicans and Cubans), having an ED visit (Cubans, Central Americans, and other Latinos), and visiting a physician (non-Latino whites, Mexicans, Cubans, and Central Americans).

\section{Characteristics of the Sample}

Table 1 shows the characteristics of the sample by Latino heritage group. All characteristics were significantly different across heritage groups. Puerto Ricans composed the largest proportion of USborn individuals, whereas Mexicans had the largest proportion of noncitizens. Puerto Ricans had the largest proportion of individuals completing the interview in English, whereas Cubans had the largest proportion completing the interview in Spanish.

\section{Impact of Latino Heritage Group, Nativity, Language, and Survey Year on Access to and Utilization of Health Care}

Table 2 shows logistic regression models for all outcomes. Health care access and utilization varied significantly across survey periods. The odds of being insured were greater in 2014 and 2015 relative to 2011, whereas the odds of delaying care or forgoing care were lower in 2014 and 2015 than in
2011. Odds of seeking care in an ED were lower in 2014 than in 2011, whereas odds of having a physician visit were greater in 2014 than in 2011. Mexicans and Central Americans had lower odds of being insured relative to non-Latino whites. Mexicans had lower odds of delaying care than nonLatino whites. Cubans and Central Americans had higher odds of forgoing any care relative to nonLatino whites. Puerto Ricans and other Latinos had higher odds of using the ED when compared with non-Latino whites. Mexicans had lower odds of using the ED and having a physician visit when compared with non-Latino whites.

Also shown in Table 2, naturalized citizens and noncitizens had lower odds of being insured than US-born citizens. Noncitizens had lower odds of using an ED than US-born citizens. Naturalized citizens had higher odds and noncitizens had lower odds of having a physician visit than US-born citizens. Respondents who completed the NHIS in Spanish had lower odds of being insured, forgoing care, using an ED, and having a physician visit when compared with respondents who completed the NHIS in English. Respondents who completed the NHIS in another language had lower odds of being insured when compared with respondents who completed the NHIS in English.

\section{Impact of ACA on Heritage Group Disparities}

Table 3 shows models with Latino heritage group $\times$ time period interaction terms. Results 


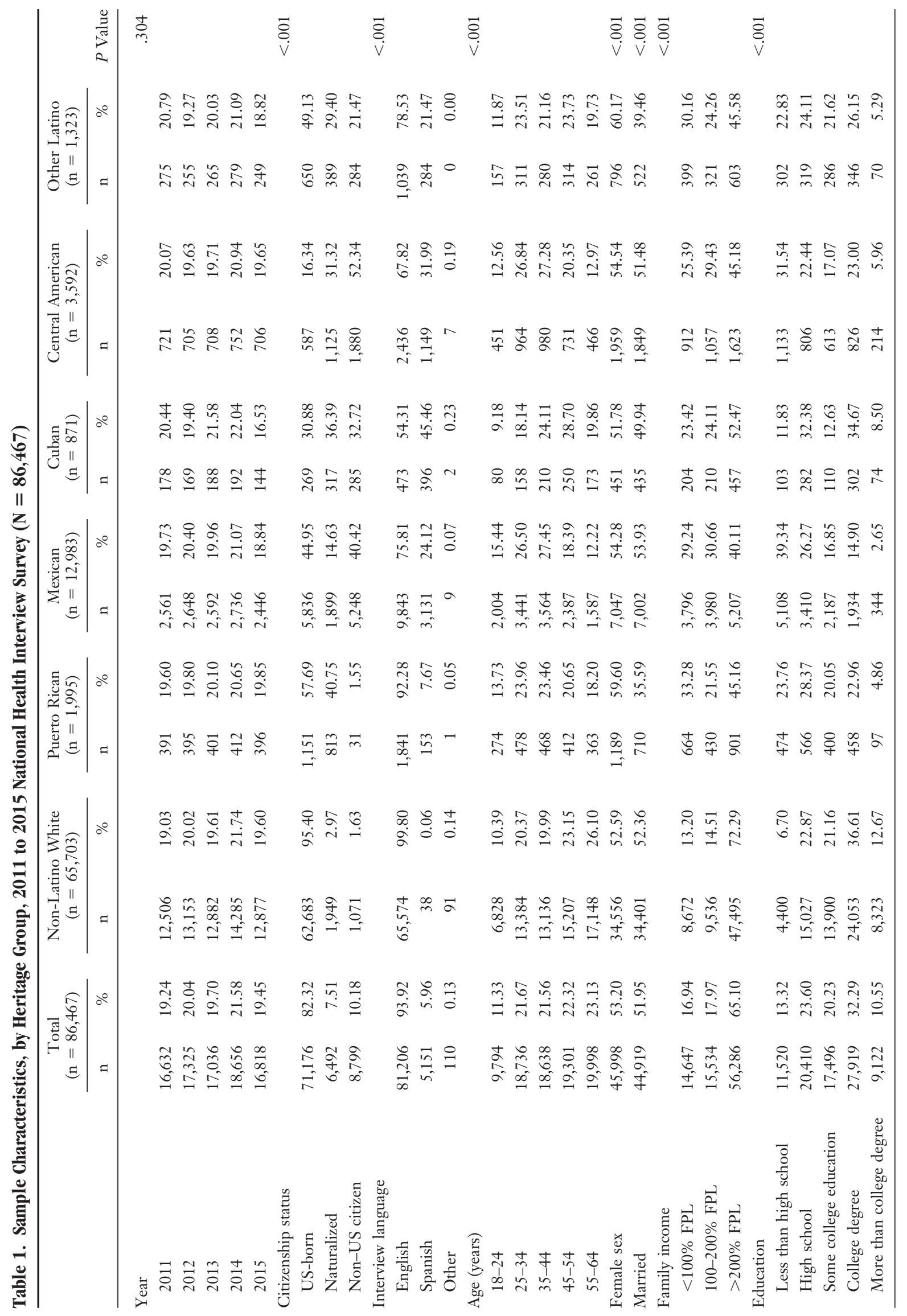




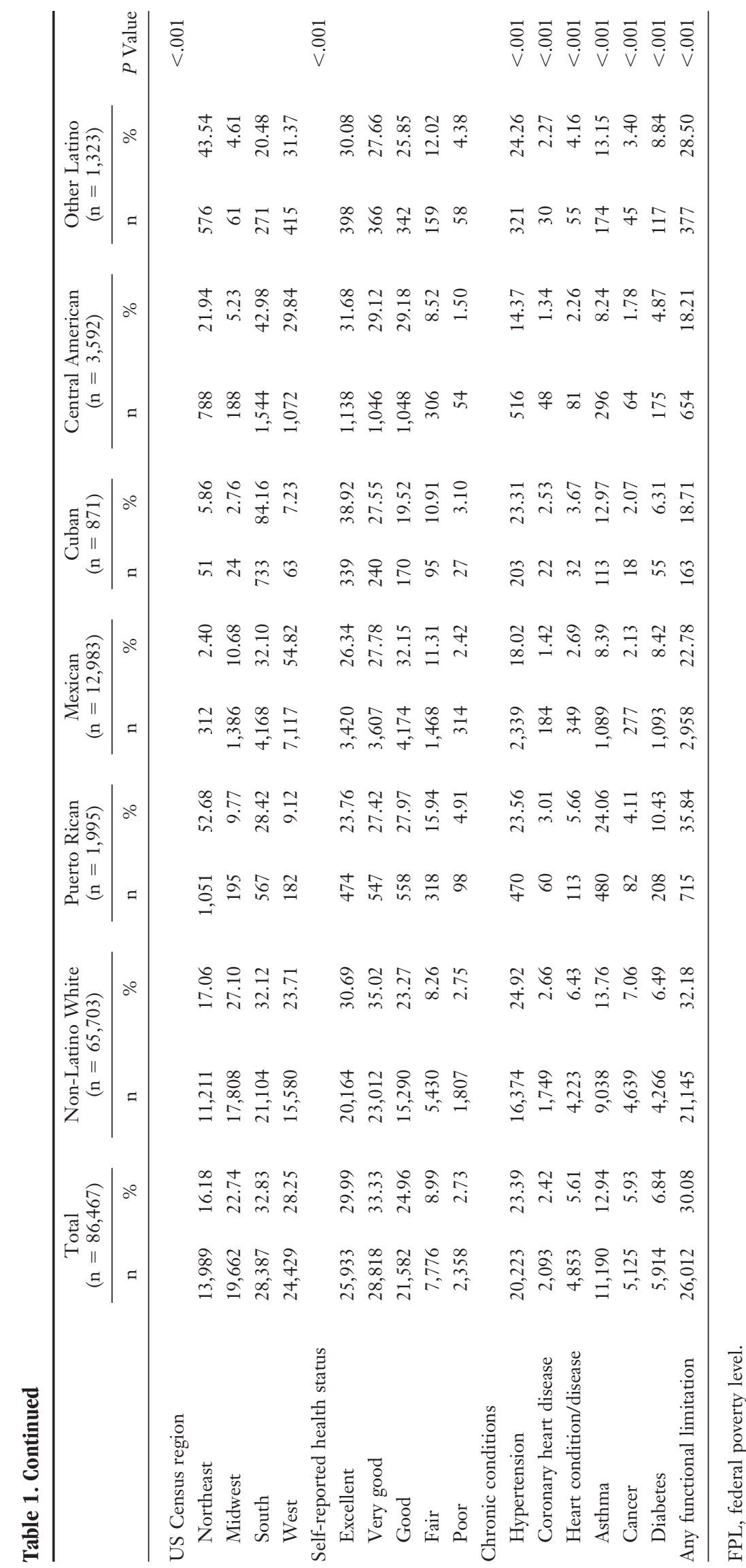


Table 2. Odds of Access and Utilization of Health Care as a Function of Year, Heritage Group, Citizenship Status, and Interview Language, 2011 to 2015 National Health Interview Survey $(\mathrm{N}=86,467)$

\begin{tabular}{|c|c|c|c|c|c|c|c|c|c|c|}
\hline & \multicolumn{2}{|c|}{ Insured } & \multicolumn{2}{|c|}{ Delay in Care } & \multicolumn{2}{|c|}{ Forgo Care } & \multicolumn{2}{|c|}{ ED Use } & \multicolumn{2}{|c|}{ Physician Visit } \\
\hline & OR & $95 \% \mathrm{CI}$ & OR & $95 \% \mathrm{CI}$ & OR & $95 \% \mathrm{CI}$ & OR & $95 \% \mathrm{CI}$ & OR & $95 \% \mathrm{CI}$ \\
\hline \multicolumn{11}{|l|}{ Year } \\
\hline \multicolumn{11}{|l|}{2011} \\
\hline 2012 & 1.03 & $0.96-1.10$ & 0.91 & $0.85-0.98$ & 0.97 & $0.90-1.05$ & 0.96 & $0.89-1.03$ & 0.97 & $0.92-1.03$ \\
\hline 2013 & 1.02 & $0.95-1.10$ & $0.81^{*}$ & $0.75-0.87$ & $0.90^{\dagger}$ & $0.82-0.98$ & 0.95 & $0.89-1.02$ & 1.01 & $0.96-1.07$ \\
\hline 2014 & $1.43^{*}$ & $1.32-1.55$ & $0.75^{*}$ & $0.69-0.81$ & $0.77^{*}$ & $0.70-0.85$ & $0.92^{\dagger}$ & $0.86-0.99$ & $1.13^{*}$ & $1.06-1.20$ \\
\hline 2015 & $1.82^{*}$ & $1.68-1.98$ & $0.63^{*}$ & $0.58-0.69$ & $0.67^{*}$ & $0.61-0.73$ & 0.93 & $0.86-1.01$ & 1.03 & $0.97-1.09$ \\
\hline \multicolumn{11}{|l|}{ Heritage group } \\
\hline \multicolumn{11}{|l|}{ Non-Latino white } \\
\hline Puerto Rican & 1.05 & $0.90-1.22$ & 0.86 & $0.72-1.03$ & 0.94 & $0.78-1.14$ & $1.42^{*}$ & $1.24-1.63$ & 0.90 & $0.79-1.02$ \\
\hline Mexican & $0.68^{*}$ & $0.63-0.73$ & $0.83^{*}$ & $0.77-0.91$ & 0.96 & $0.87-1.06$ & $0.83^{*}$ & $0.77-0.91$ & $0.87^{*}$ & $0.82-0.93$ \\
\hline Cuban & 0.98 & $0.75-1.29$ & 1.08 & $0.88-1.34$ & $1.33^{\dagger}$ & $1.02-1.73$ & 1.15 & $0.88-1.51$ & 0.96 & $0.82-1.13$ \\
\hline Central American & $0.66^{*}$ & $0.59-0.74$ & 1.08 & $0.94-1.24$ & $1.28^{*}$ & $1.10-1.49$ & 1.07 & $0.94-1.22$ & 1.01 & $0.91-1.11$ \\
\hline Other Latinos & 1.01 & $0.84-1.22$ & 0.92 & $0.75-1.13$ & 0.99 & $0.79-1.24$ & $1.25^{\dagger}$ & $1.07-1.46$ & 0.90 & $0.78-1.02$ \\
\hline \multicolumn{11}{|l|}{ Citizenship status } \\
\hline \multicolumn{11}{|l|}{ US-born } \\
\hline Naturalized & $0.86^{*}$ & $0.78-0.95$ & 0.96 & $0.86-1.07$ & 1.03 & $0.90-1.17$ & 0.92 & $0.83-1.01$ & $1.09^{\dagger}$ & $1.01-1.17$ \\
\hline Non-US citizen & $0.34^{*}$ & $0.31-0.37$ & 1.10 & $0.99-1.24$ & 1.12 & $1.00-1.26$ & $0.78^{*}$ & $0.69-0.88$ & $0.74^{*}$ & $0.68-0.80$ \\
\hline \multicolumn{11}{|l|}{ Interview language } \\
\hline \multicolumn{11}{|l|}{ English } \\
\hline Spanish & $0.79^{*}$ & $0.71-0.87$ & 1.05 & $0.93-1.18$ & $0.86^{\dagger}$ & $0.75-0.98$ & $0.62^{*}$ & $0.55-0.71$ & $0.80^{*}$ & $0.74-0.87$ \\
\hline Other & $0.55^{\dagger}$ & $0.31-0.98$ & 0.61 & $0.29-1.31$ & 0.53 & $0.27-1.04$ & 0.80 & $0.35-1.82$ & 0.80 & $0.55-1.17$ \\
\hline
\end{tabular}

Models also control for age, sex, marital status, family income, education, US Census region, self-reported health status, chronic conditions, and functional limitations.

${ }^{*} P<.01$.

${ }^{\dagger} P<.05$.

CI, confidence interval; ED, emergency department; OR, odds ratio.

suggest that odds of delaying care were significantly lower among non-Latino whites in the period after the ACA relative to the period before the ACA. Furthermore, the reduction in odds of delaying care was significantly greater among Mexicans and Puerto Ricans than among non-Latino whites. Similarly, odds of forgoing care were significantly greater in the period after the ACA among nonLatino whites. There was no significant difference in this change over time between whites and most Latino heritage groups. The exception was Puerto Ricans, who experienced a larger reduction in odds of forgoing care relative to whites. Results also suggest that odds of ED use did not vary across periods among non-Latino whites. However, odds of ED use among Puerto Ricans fell significantly over time periods relative to non-Latino whites. Finally, odds of having a physician visit increased significantly among whites in the period after the ACA, with few significant differences in this change between whites and most Latino subgroups. The exception is that Central Americans experienced a significantly greater increase in the odds of having a physician visit than non-Latino whites experienced.

\section{Impact of ACA on Language and Citizenship Status Disparities}

Table 4 shows the models with citizenship $\times$ time period interaction terms. No interaction term was significant for citizenship status and time period. The period after the ACA was associated with a reduction in the disparity of having a physician visit between respondents who completed the NHIS in Spanish relative to those completing it in English.

\section{Discussion}

Trends in access to and utilization of health care revealed that most Latino heritage groups achieved improved access to and utilization of health care for 
Table 3. Odds of Access and Utilization of Health Care as a Function of Year and Heritage Group Interaction Citizenship, 2011 to 2015 National Health Interview Survey $(\mathrm{N}=86,467)$

\begin{tabular}{|c|c|c|c|c|c|c|c|c|c|c|}
\hline & \multicolumn{2}{|c|}{ Insured } & \multicolumn{2}{|c|}{ Delay in Care } & \multicolumn{2}{|c|}{ Forgo Care } & \multicolumn{2}{|c|}{ ED Use } & \multicolumn{2}{|c|}{ Physician Visit } \\
\hline & OR & $95 \% \mathrm{CI}$ & OR & $95 \% \mathrm{CI}$ & OR & $95 \% \mathrm{CI}$ & OR & $95 \% \mathrm{CI}$ & OR & $95 \% \mathrm{CI}$ \\
\hline \multicolumn{11}{|l|}{ Heritage } \\
\hline \multicolumn{11}{|l|}{ Non-Latino white } \\
\hline Puerto Rican & 1.05 & $0.88-1.26$ & 0.97 & $0.78-1.19$ & 1.16 & $0.93-1.44$ & $1.59^{*}$ & $1.36-1.85$ & 0.94 & $0.81-1.09$ \\
\hline Mexican & $0.67^{*}$ & $0.62-0.73$ & $0.89^{\dagger}$ & $0.81-0.98$ & 1.00 & $0.89-1.12$ & $0.81^{*}$ & $0.74-0.89$ & $0.85^{*}$ & $0.79-0.91$ \\
\hline Cuban & 0.91 & $0.71-1.17$ & 1.22 & $0.94-1.58$ & $1.52^{\dagger}$ & $1.10-2.10$ & $1.32^{+}$ & $1.05-1.65$ & 1.01 & $0.83-1.22$ \\
\hline Central American & $0.63^{*}$ & $0.55-0.72$ & 1.10 & $0.93-1.29$ & $1.35^{*}$ & $1.14-1.60$ & 1.10 & $0.94-1.28$ & 0.92 & $0.81-1.04$ \\
\hline Other Latinos & 1.14 & $0.90-1.43$ & 0.82 & $0.63-1.07$ & 0.92 & $0.70-1.20$ & $1.25^{\dagger}$ & $1.04-1.50$ & 0.91 & $0.76-1.08$ \\
\hline \multicolumn{11}{|l|}{ Time period } \\
\hline \multicolumn{11}{|l|}{ Before ACA } \\
\hline After ACA & $1.56^{*}$ & $1.46-1.67$ & $0.78^{*}$ & $0.74-0.84$ & $0.78^{*}$ & $0.72-0.84$ & 0.96 & $0.91-1.01$ & $1.07^{*}$ & $1.02-1.12$ \\
\hline \multicolumn{11}{|l|}{ Heritage group $\times$ time period } \\
\hline \multicolumn{11}{|l|}{ White $\times$ after ACA } \\
\hline Puerto Rican $\times$ after ACA & 0.98 & $0.72-1.32$ & $0.71^{\dagger}$ & $0.52-0.98$ & $0.53^{*}$ & $0.35-0.79$ & $0.76^{+}$ & $0.60-0.97$ & 0.88 & $0.70-1.11$ \\
\hline Mexican $\times$ after ACA & 1.03 & $0.92-1.16$ & $0.82^{\dagger}$ & $0.71-0.95$ & 0.90 & $0.76-1.06$ & 1.07 & $0.94-1.22$ & 1.07 & $0.97-1.17$ \\
\hline Cuban $\times$ after ACA & 1.21 & $0.85-1.73$ & 0.70 & $0.43-1.15$ & 0.64 & $0.39-1.06$ & 0.67 & $0.38-1.17$ & 0.90 & $0.70-1.17$ \\
\hline Central American $\times$ after ACA & 1.15 & $0.94-1.40$ & 0.94 & $0.74-1.21$ & 0.86 & $0.65-1.14$ & 0.94 & $0.74-1.20$ & $1.25^{\dagger}$ & $1.04-1.49$ \\
\hline Other Latino $\times$ after ACA & 0.73 & $0.54-1.00$ & 1.32 & $0.86-2.04$ & 1.22 & $0.78-1.90$ & 1.01 & $0.75-1.34$ & 0.97 & $0.73-1.30$ \\
\hline
\end{tabular}

Models also control for citizenship status, interview language, age, sex, marital status, family income, education, US Census region, self-reported health status, chronic conditions, and functional limitations.

${ }^{*} P<.01$.

${ }^{\dagger} P<.05$.

ACA, Patient Protection and Affordable Care Act; CI, confidence interval; OR, odds ratio.

most measures relative to 2011. However, between 2014 and 2015, many Latino subgroups experienced increases in delaying or forgoing care and ED visits, suggesting that the provisions in the ACA have only resulted in short-term gains. This trend must be monitored further to better understand its long-term impact, especially given predictions that health care premiums are expected to rise under the ACA-implemented insurance marketplace. ${ }^{41}$ As a result, longterm efforts to improve access to and utilization of health care among Latinos may necessitate policies to drive down the cost of care.

Results suggest that the ACA has been successful in reducing some disparities in access to and utilization of care between non-Latino whites and specific Latino heritage groups. For example, Puerto Ricans had the greatest gains, with reduced disparities in delaying care, forgoing care, and using the ED. Mexicans and Central Americans saw disparities in delaying care and having a physician visit, respectively. The latter finding may be in part because of the worsening pattern of visiting a physician among non-Latino whites. Importantly, no group saw reductions in disparities in insurance status. While these findings suggest that certain groups have benefited more from the ACA than others, additional differences may be obscured by the differential degree and rate of ACA expansion exhibited across states. For example, Florida, which is home to the majority of Cuban-heritage individuals in the United States, has elected to not expand Medicaid, ${ }^{42}$ thus undermining the potential benefit of ACA among this group. Conversely, California, which is home to a plurality of Mexican-heritage individuals, implemented an early expansion of coverage for low-income groups, ${ }^{10,11}$ thus allowing gains to be more fully realized but also potentially diminishing the impact of years 2014 and 2015 as proxies for full ACA implementation. Moreover, California is expanding Marketplace coverage, without subsidies, to undocumented individuals, but the NHIS data included in these analyses do not capture these recent policy changes.

Results also highlight the relative lack of impact the ACA has had in reducing disparities in access to and utilization of health care among Latinos. Specifically, disparities by citizenship or language (with only 1 exception) did not dissipate with the passage 
Table 4. Odds of Access and Utilization of Health Care as a Function of Year and Citizenship Status or Interview Language Interactions, 2011 to 2015 National Health Interview Survey

\begin{tabular}{|c|c|c|c|c|c|c|c|c|c|c|}
\hline & \multicolumn{10}{|c|}{ Outcome } \\
\hline & \multicolumn{2}{|c|}{ Insured } & \multicolumn{2}{|c|}{ Delay in Care } & \multicolumn{2}{|c|}{ Forgo Care } & \multicolumn{2}{|c|}{ ED Use } & \multicolumn{2}{|c|}{ Physician Visit } \\
\hline & OR & $95 \% \mathrm{CI}$ & OR & $95 \%$ CI & OR & $95 \%$ CI & OR & $95 \%$ CI & OR & $95 \% \mathrm{CI}$ \\
\hline \multicolumn{11}{|l|}{$\begin{array}{l}\text { Citizenship } \times \text { time period* } \\
\quad(\mathrm{n}=20,764)\end{array}$} \\
\hline \multicolumn{11}{|l|}{ US-born $\times$ after ACA } \\
\hline Naturalized $\times$ after ACA & 0.98 & $0.82-1.17$ & 1.05 & $0.83-1.32$ & 1.09 & $0.84-1.40$ & 1.02 & $0.84-1.24$ & 1.10 & $0.94-1.28$ \\
\hline Non-US citizen $\times$ after ACA & 1.03 & $0.81-1.30$ & 0.80 & $0.62-1.03$ & 0.83 & $0.62-1.12$ & 0.94 & $0.76-1.16$ & 1.15 & $0.96-1.36$ \\
\hline \multicolumn{11}{|l|}{$\begin{array}{l}\text { Interview language } \times \text { time period }^{\dagger} \\
\quad(\mathrm{n}=20,745)\end{array}$} \\
\hline \multicolumn{11}{|l|}{ English $\times$ after ACA } \\
\hline Spanish $\times$ after ACA & 1.02 & $0.87-1.20$ & 0.97 & $0.79-1.19$ & 0.92 & $0.74-1.14$ & 0.96 & $0.76-1.22$ & $1.17^{\ddagger}$ & $1.01-1.37$ \\
\hline
\end{tabular}

*Models also control for race, interview language, age, sex, marital status, family income, education, US Census region, self-reported health status, chronic conditions, and functional limitations.

${ }^{\dagger}$ Models also control for race, citizenship, age, sex, marital status, family income, education, US Census region, self-reported health status, chronic conditions, and functional limitations. These analyses excluded individuals who completed the National Health Interview Survey in a language other than English or Spanish.

${ }^{\ddagger} P<.05$.

ACA, Patient Protection and Affordable Care Act; CI, confidence interval; ED, emergency department; OR, odds ratio.

of the ACA. The lack of the importance of language contrasts with previous state-level findings showing the ACA as having the greatest benefits for individuals with LEP. ' As a result, additional efforts may be needed to improve knowledge of the ACA and facilitate enrollment in coverage options among Spanish-speaking individuals. However, this discrepancy may be a result of the limited sample of Spanish-speaking respondents in the NHIS. In addition, because the insurance expansions created by the ACA began in January 2014, they are subject to an extended open enrollment period (which means that some individuals started coverage as late as May 1, 2014) and were phased in over time. Individuals who were harder to reach, younger, and healthier may have been less likely to enroll and benefit from health insurance coverage during 2014. ${ }^{43}$ As a result, data collected during 2014 may bias the findings of this study toward the null.

The persistent disparities between citizens and noncitizens is not surprising because the ACA prohibits undocumented individuals from gaining coverage from public sources or from private sources obtained in insurance exchanges. ${ }^{26}$ Similarly, lawful permanent residents must undergo a 5 -year waiting period in most states before they are eligible for ACA benefits under Medicaid. ${ }^{37}$ Furthermore, the ACA did not address larger structural and economic issues that discourage noncitizens from seeking health care (ie, a historic number of immigrant deportations, ${ }^{44}$ cheaper health care abroad ${ }^{45,46}$ and universal health care in most Latin American countries ${ }^{47,48}$ ). Thus, by design, the ACA has limited ability to address the needs of noncitizens. However, the ACA did allocate funding to support existing community health centers (CHCs) and build future $\mathrm{CHCs}^{49}{ }^{49}$ Because almost all CHCs offer services regardless of insurance coverage or ability to pay, undocumented individuals may still have a way to benefit from the ACA. Given that disparities between citizens and noncitizens did not dissipate, the current levels of increased investment in CHCs are an unlikely policy mechanism to address this disparity. In terms of naturalized citizens, results suggest that there were few disparities to close, but it is notable that the ACA did not reduce the disparities in rates of insurance coverage, indicating a future opportunity for targeted policy interventions.

While this study provides unique insight into disparities in the impact of the ACA among Latinos, there are a few limitations to consider. First, the years 2014 and 2015 can only serve as a rough marker for ACA implementation because not all states followed the same implementation timeline. Similarly, using years as a marker does not indicate which of the many mechanisms in the ACA is driving reductions in disparities. Second, the measure of language does not capture proficiency in 
English and thus may explain why these results do not mirror previous results examining LEP. Finally, the measure of citizenship may also be crude in examining the ACA's impact, since there is no way of knowing who is a lawful permanent resident and whether he or she has met the ACA's 5-year waiting period in those states with that exclusion.

\section{Conclusion}

Despite limitations, this study suggests that the ACA has had some success in reducing disparities in access to and utilization of health care for Latinos. As a result, wide-reaching reforms like the ACA may be effective at reducing disparities and improving public health. The decision by several states not to expand Medicaid coverage will limit this impact given that many states with sizable proportions of Latinos (ie, Florida, Texas, and Utah) have elected not to undergo this expansion. Despite this, current efforts by other states, including recently passed legislation in California to allow undocumented immigrants to purchase coverage in insurance exchanges without subsidies,${ }^{50}$ suggest that the ACA may only be a starting point in the effort to improve access to and utilization of health care for Latinos. These expansion efforts, however, are contingent on approval from the federal government. With repeal of ACA provisions being considered by the next presidential administration these expansions seem unlikely. As a result, some of the progress made under the ACA may be reversed.

To see this article online, please go to: http://jabfm.org/content/ 30/1/52.full.

\section{References}

1. Blumenthal D, Abrams M, Nuzum R. The Affordable Care Act at 5 years. N Engl J Med 2015;372:2451-8.

2. Golberstein E, Busch SH, Zaha R, Greenfield SF, Beardslee WR, Meara E. Effect of the Affordable Care Act's young adult insurance expansions on hospital-based mental health care. Am J Psychiatry 2015;172:182-9.

3. Wharam JF, Zhang F, Landon BE, LeCates R, Soumerai S, Ross-Degnan D. Colorectal cancer screening in a nationwide high-deductible health plan before and after the Affordable Care Act. Med Care 2016;54:466-73.

4. Cooper GS, Kou TD, Schluchter MD, Dor A, Koroukian SM. Changes in receipt of cancer screening in medicare beneficiaries following the Affordable Care Act. J Natl Cancer Inst 2016;108. pii: djv374.

5. Courtemanche C, Marton J, Yelowitz A. Who gained insurance coverage in 2014, the first year of full ACA implementation? Health Econ 2016;25:778-84.
6. Chen J, Vargas-Bustamante A, Mortensen K, Ortega AN. Racial and ethnic disparities in health care access and utilization under the Affordable Care Act. Med Care 2016;54:140-6.

7. Ortega AN, Rodriguez HP, Vargas Bustamante A. Policy dilemmas in Latino health care and implementation of the Affordable Care Act. Annu Rev Public Health 2015;36:525-44.

8. Mosqueira AG, Hua LM, Sommers BD. Racial differences in awareness of the Affordable Care Act and application assistance among low-income adults in three southern states. Inquiry 2015;52. pii: 0046958015609607.

9. Heintzman J, Bailey SR, DeVoe J, et al. In lowincome Latino patients, post-Affordable Care Act insurance disparities may be reduced even more than broader national estimates: evidence from Oregon. J Racial Ethn Health Disparities 2016 April 22 [Epub ahead of print].

10. Sommers BD, Kenney GM, Epstein AM. New evidence on the Affordable Care Act: coverage impacts of early medicaid expansions. Health Aff (Millwood) 2014;33:78-87.

11. Lo N, Roby DH, Padilla J, et al. Increased service use following Medicaid expansion is mostly temporary: evidence from California's low income health program. Policy Brief UCLA Cent Health Policy Res 2014;(PB2014-7):1-8.

12. Sommers BD, Chua K-P, Kenney GM, Long SK, McMorrow S. California's early coverage expansion under the Affordable Care Act: a county-level analysis. Health Serv Res 2015;51:825-45.

13. Derose KP, Baker DW. Limited English proficiency and Latinos' use of physician services. Med Care Res Rev 2000;57:76-91.

14. Schur CL, Albers MLA. Language, sociodemographics, and health care use of Hispanic adults. J Health Care Poor Underserved 1996;7:140-58.

15. Timmins CL. The impact of language barriers on the health care of Latinos in the United States: a review of the literature and guidelines for practice. J Midwifery Womens Health 2002;47:80-96.

16. Ortega AN, Fang H, Perez VH, et al. Health care access, use of services, and experiences among undocumented Mexicans and other Latinos. Arch Intern Med 2007;167:2354-60.

17. Durazo EM, Wallace SP. Access to health care across generational status for Mexican-origin immigrants in California. Field Actions Science Reports. J Field Actions 2014:1-10.

18. Alegría M, Mulvaney-Day N, Woo M, Torres M, Gao S, Oddo V. Correlates of past-year mental health service use among Latinos: results from the National Latino and Asian American Study. Am J Public Health 2007;97:76-83.

19. Ku L, Matani S. Left out: immigrants' access to health care and insurance. Health Aff (Millwood) 2001;20:247-56. 
20. Vargas Bustamante A, Fang H, Garza J, et al. Variations in healthcare access and utilization among Mexican immigrants: the role of documentation status. J Immigr Minor Health 2012;14:146-55.

21. Berk ML, Schur CL. The effect of fear on access to care among undocumented Latino immigrants. J Immigr Health 2001;3:151-6.

22. Heyman JM, Núñez GG, Talavera V. Healthcare access and barriers for unauthorized immigrants in El Paso County, Texas. Fam Community Health 2009;32:4-21.

23. Bergmark R, Barr D, Garcia R. Mexican immigrants in the US living far from the border may return to Mexico for health services. J Immigr Minor Health 2010;12:610-4.

24. Macias EP, Morales LS. Crossing the border for health care. J Health Care Poor Underserved 2001; 12:77-87.

25. De Jesus M, Xiao C. Cross-border health care utilization among the Hispanic population in the United States: implications for closing the health care access gap. Ethn Health 2013;18:297-314.

26. Zuckerman S, Waidmann TA, Lawton E. Undocumented immigrants, left out of health reform, likely to continue to grow as share of the uninsured. Health Aff (Millwood) 2011;30:1997-2004.

27. Roby DH, Watson G, Jacobs K, et al. Modeling the impact of the Affordable Care Act and the individual mandate on Californians. J Fam Econ Issues 2013;34: 16-28.

28. Shah NS, Carrasquillo O. Twelve-year trends in health insurance coverage among Latinos, by subgroup and immigration status. Health Aff (Millwood) 2006;25:1612-9.

29. Rosales M, Gonzalez P. Mammography screening among Mexican, Central-American, and South-American women. J Immigr Minor Health 2012;15:225-33.

30. Perez VH, Fang H, Inkelas M, Kuo AA, Ortega AN. Access to and utilization of health care by subgroups of Latino children. Med Care 2009;47:695-9.

31. Escarce JJ, Kapur K. Access to and quality of health care. In: Tienda M, Mitchell F, editors. Hispanics and the future of America. Washington, DC: National Academies Press; 2006. p. 410-446.

32. Vargas Bustamante A, Chen J, Rodriguez HP, Rizzo JA, Ortega AN. Use of preventive care services among Latino subgroups. Am J Prev Med 2010;38:610-9.

33. Portes A, Fernández-Kelly P, Haller W. Segmented assimilation on the ground: the new second generation in early adulthood. Ethn Racial Stud 2005;28:1000-40.

34. Motel S, Patten E. Hispanic origin profiles, 2010. Washington, DC: Pew Research Center; 2012. Available from: http://www.pewhispanic.org/2012/06/ 27/country-of-origin-profiles/-rankings-2010. Accessed November 10, 2016.

35. Alcalá HE, Albert SL, Roby DH, et al. Access to care and cardiovascular disease prevention: a cross-sectional study in 2 Latino communities. Medicine 2015;94: e1441.

36. Alcalá HE, Albert SL, Trabanino SK, et al. Access to and use of health care services among Latinos in East Los Angeles and Boyle Heights. Fam Community Health 2016;39:62-71.

37. Healthcare.gov. Coverage for lawfully present immigrants. Baltimore, MD: U.S. Centers for Medicare \& Medicaid Services; 2012. Available from: https://www.healthcare.gov/immigrants/lawfullypresent-immigrants/. Accessed May 25, 2016.

38. Chen J, Bustamante AV, Tom SE. Health care spending and utilization by race/ethnicity under the Affordable Care Act's dependent coverage expansion. Am J Public Health 2015;105(Suppl 3):S499-507.

39. Mood C. Logistic regression: why we cannot do what we think we can do, and what we can do about it. Eur Sociol Rev 2010;26:67-82.

40. VanderWeele TJ. Mediation analysis: a practitioner's guide. Annu Review Public Health 2016;37:17-32.

41. Sullivan P. ObamaCare premiums expected to rise sharply amid insurer losses. The Hill, April 25, 2016.

42. Kaiser Family Foundation. Status of state action on the Medicaid expansion decision. 2016. Available from: http://kff.org/health-reform/state-indicator/stateactivity-around-expanding-medicaid-under-theaffordable-care-act/. Accessed May 24, 2016.

43. Patient Protection and Affordable Care Act. 42 USC \$ 18001, 2010.

44. Lopez MH, Gonzalez-Barrera A, Motel S. As deportations rise to record levels, most Latinos oppose Obama's policy. Washington, DC: Pew Research Center; 2011. Available from: http://www.pewresearch. org/2011/12/28/as-deportations-rise-to-record-levelsmost-latinos-oppose-obamas-policy/. Accessed November 10, 2016.

45. Boyer LV. On 1000-fold pharmaceutical price markups and why drugs cost more in the United States than in Mexico. Am J Med 2015;128:1265-7.

46. Gan LL, Frederick JR. Medical tourists: who goes and what motivates them? Health Mark Q 2013;30: 177-94.

47. Knaul FM, González-Pier E, Gómez-Dantés O, et al. The quest for universal health coverage: achieving social protection for all in Mexico. Lancet 2012;380: 1259-79.

48. Atun R, de Andrade LOM, Almeida G, et al. Healthsystem reform and universal health coverage in Latin America. Lancet 2015;385:1230-47.

49. Health centers and the Affordable Care Act. Rockville, MD: U.S. Department of Health and Human Services; 2016. Available from: http://www.bphc. hrsa.gov/about/healthcentersaca/index.html. Accessed September 16, 2016.

50. Khurram S. California law to help undocumented immigrants purchase health insurance. Daily Californian, June 15, 2016. 